\title{
RESENHA
}

Sociologias, Porto Alegre, ano 16, no 37, set/dez 2014, p. 306-318

\section{Abusos policiales. La fuerza pública y sus usos}

JOBARD, Fabien. Abusos policiales. La fuerza pública y sus usos. $1^{\mathrm{a}}$

Ed. Buenos Aires: Prometeo Libros, 2011.

\section{Resumo}

A obra retrata pesquisa realizada por Fabien Jobard, que delineou sua teoria sobre a polícia a partir de análises das ações de violência policial, comprovadas por entrevistas concedidas por pessoas que sofreram esses atos de "ilegalismos" e pelo cruzamento desses relatos com os discursos da imprensa e dos tribunais franceses. O resultado foi o quadrilátero de condições de violência policial, a saber: a pureza penal da pessoa agredida, a possibilidade de o policial ser responsabilizado pela violência, a credibilidade das testemunhas e a circunstância do atendimento policial. Sua narrativa genealógica possibilita uma melhor compreensão do Estado, da violência (legítima e ilegítima) e da polícia.

Palavras-chave: Polícia. Violência policial. Dominação legal.

"Faculdade Católica Rainha da Paz, Araputanda, Mato Grosso, Brasil.

http://dx.doi.org/10.1590/15174522-016003731 
Police abuses. The public force and their uses

\begin{abstract}
The book describes research by Fabien Jobard, who developed his theory about the police through the analysis of police violence incidents, supported by interviews with people who experienced these unlawful acts and by matching these testimonies to the discourses of both the press and the French courts. The result was the framework of conditions that could trigger police violence, namely: the criminal purity of the person assaulted, the possibility of the police officer being blamed for the violence, the credibility of the witnesses, and the circumstances of the police service. His genealogic narrative provides a better understanding of the state, the violence (legitimate and illegitimate) and the police.
\end{abstract}

Keywords: Police. Police violence. Legal domination.

Fabien Jobard é Diretor do Centre de Recherche Sociologique sur Le Droit et les Institutions Pénales (CESDIP), órgão vinculado ao Centre National de Recherche Sociologique (CNRS) da França, e dedica-se às questões dos efeitos sociais das leis de segurança e das instituições policiais na França e na Europa. A obra, intitulada: Abusos policiales. La fuerza pública y sus usos, foi publicada no ano de 2011 pela Editora Prometeo Libros, de Buenos Aires (Argentina), originalmente publicada em francês, em 2002, pela Editora La Découverte, de Paris (França).

O livro está distribuído em três partes, sendo elas: 1) Os relatos de violência; 2) A prova dos fatos; e 3) Dar força à lei. Essa distribuição não é aleatória e segue uma construção de conhecimento, pela qual o autor procura traçar uma genealogia dos atos ilegais praticados pela polícia, permitindo assim melhor compreender o Estado, a violência e a polícia.

A base introdutória narra os autos de um processo tramitado na Corte Europeia de Direitos Humanos (CEDH), Selmouci VS France, Estrasburgo, Requerimento no 25803/94, no qual a França foi condenada por 
tortura policial contra Ahmed Selmouni, contrariamente ao que aconteceu na Corte de Apelação francesa, que deixou em liberdade os policiais acusados. Para Jobard, os relatos existentes sobre a violência policial não permitem entender as condições nas quais esses mesmos relatos tomam uma forma homogênea, nem tampouco compreender as relações que vinculam esses elementos à rotina policial, bem como à natureza do Estado. O autor afirma que uma coleção de fatos heterogêneos serve para constituir, em cada caso particular, uma prova incandescente do caráter bárbaro de uma profissão sem alma, conforme Jean Paul Sartre já havia alertado quando disse que o Estado não é fascista, mas sua polícia sim.

É nesse percurso que Jobard nos apresenta sua metodologia de pesquisa que, fundada no interacionismo simbólico, busca como ponto de partida a definição penal de violência e a investigação das emoções individuais de quem foi vítima de violência policial, em três movimentos, quais sejam: 1) as entrevistas que fizeram a composição do material discursivo; 2) a verificação dos pontos comuns e homologias dentro de um espaço de probabilidade das violências policiais; e 3) a dedução, na ordem dos fatos sociais e das normas jurídicas, na ordem da sociedade e na ordem do Estado, do conjunto de condições de possibilidade das violências.

Em Relatos de violência (primeira parte), Jobard relata a dificuldade de se encontrar - e onde encontrar - pessoas que foram vítimas de violência policial e que estejam dispostas a falar. A eleição foi limitada, mas orientada às pessoas que têm como propriedade comum a alta probabilidade de haver experimentado "encontros" com a polícia e com passagem pelo sistema prisional. Essas pessoas podem suscitar problemas de representatividade e credibilidade aos seus testemunhos, sendo usada como estratégia de investigação a restauração da coerência interna discursiva ligada ao quadro de representação de marginalidade na França no ano de 1994.

Os determinantes da violência policial são apresentados, sobretudo quem está na clientela potencial dessa violência, refletida nas pessoas que 
passaram pelo sistema penal e que ocupam as ruas. Tais pessoas, vistas como em estado anômico, forçam uma luta da polícia por sua ressocialização, pois essa polícia é a única autoridade em via pública e, portanto, deve fazer/deixar fluir a circulação na rua, prendendo, normalmente, os autores de atos descritos como crimes, tais como roubo de veículos, furtos, etc.

A polícia, como hipóstase da sociedade política, subsume-se à sociedade civil e ao Estado, e também é vista como o Estado armado, o Estado que garante a execução das condenações judiciais. Já os policiais, objetos de empatia, servem como influência para uma reivindicação de pertencimento social por aqueles mesmos contra quem se emprega a violência física (p. 34). No entanto, não é possível compreender a intensidade dessa demanda de vínculo social destinada aos policiais senão for por questão dos poderes que se confiam a eles, sobretudo na França, cujo artigo 78.2 do Código de Processo Penal autoriza o controle de identidade.

A polícia é marcada pela oposição entre o mundo ordinário e o mundo policial, o que implica em dispor, contra algumas pessoas, de um poder de demarcação dos circuitos em que vai trabalhar o policial e do circuito judicial, podendo resultar em marcos de construção do mundo social, onde a desqualificação penal resulta numa desqualificação social. A polícia, no entanto, recusa essa passagem de um mundo para outro e reivindica uma prerrogativa de controlar o status social da pessoa com quem ela se encontra, sedimentando interações passadas. A relação com a polícia está sempre a relembrar a falta cometida e a identificar cada vez mais o seu autor com ela, resultando numa "irmandade" entre prisão e polícia, onde a segunda pereniza a primeira e transforma o autor do delito em delinquente. Ou seja, a polícia joga um duplo papel na definição e na concepção dos chamados marginais e, ao tempo que organiza o vínculo social, o encarna. É a polícia que autoriza a inscrição no espaço público, assinalando os lugares e os papéis em que se articula uma relação que põe em cena o recurso da violência física (p. 39-40). 
Das situações à arena, encontramos fórmulas de harmonização que são comuns aos policiais e a quem estes controlam com maior frequência, permitindo fixar os marcos comuns de percepção da realidade e os esquemas de antecipação recíproca de comportamentos com os marginalizados. Os diferentes papéis que a polícia representa lhe permitem diferenciar-se de seus interlocutores e fazer uma diferenciação entre estes, dispensando um tratamento de acordo com escala de reconhecimento. Por exemplo, as formas de ações policiais dispensadas aos assaltantes de bancos são diferentes das dispensadas aos delatores e aos violentadores de mulheres e crianças. Há nessa relação uma mescla de sentimento de consideração e ódio.

A polícia trabalha com informação e, para atingir esse fim instrumental, utiliza da transação por extorsão para fazer falar. A violência e a ameaça, como repertório de coerção, são utilizadas pela polícia como jogo para exercer pressão sobre o destino judicial da pessoa que tem à sua frente (p. 47).

O princípio da territorialidade demarca o território onde a força pública pode exercer uma competência de polícia e salvaguardar as liberdades públicas, implicando em uma gestão racional do trabalho policial, o que produz violência, da mesma forma como também produzem a anomia ou o imperativo de justiça. A estratégia consiste em: 1) racionalização do espaço de acordo com as políticas policiais; 2) controlar o espaço com imposição de quarentena; 3) governar os fluxos e movimentos dos delinquentes para inculcar disciplina territorial.

Na relação entre espaço público e ordem pública, a polícia atua de maneira a atribuir populações a territórios, usando os instrumentos legais que tem à sua disposição. A percepção da fatalidade do controle se vê confirmada posteriormente pelo controle efetivamente realizado, sobremaneira se o local é considerado como zona particular de delinquência e se indícios são observados, tais como: o fato de trocar de direção ao ver os policiais; de trocar de caminho; de errar em via pública ou de parecer 
um vagabundo; de manifestar incômodo com a passagem do veículo da polícia, posto que esse controle é realizado com base em mapas de criminalidade que conduzem a uma delimitação territorial (p. 56-58).

Nesse jogo de aparências o corpo físico ocupa um lugar central, transformando-se em vetor de pertencimento ou de subtração da arena polícia/ delinquentes, e é ele que, nessa lógica, endossa as estratégias de adaptação a esses desafios à identidade social que são as interações com a polícia.

O território considerado como meio de controle da delinquência se converte em ferramenta de compreensão do meio urbano e fixa percepções, como no caso de alguém que está onde não poderia estar. Exemplo, o negro (aparência) que está em um bairro (território) que não é considerado à sua destinação é suspeito e engendra a violência como meio menos custoso de açãopolicial (p. 62).

O espaço social de violência policial está estruturado por três dimensões, a saber: 1) a anomia que caracteriza a socialização de determinados grupos de pessoas; 2) a vinculação com as necessidades de trabalho da polícia judiciária, determinadas pelos campos policial, judicial e delitivo; e 3) a necessidade da polícia de fazer do dado geográfico um dado operativo.

O ataque ao corpo tem como representação maior o uso de algemas ${ }^{1}$, mesmo que seja somente durante o tempo de averiguação para controle de identidade, pois violenta a reputação e a dignidade da pessoa algemada. As algemas são tecnologias de degradação e de estigmatização que atentam contra a dignidade e o status e marcam a passagem do espaço urbano para o espaço policial, expulsando o indivíduo de seu espaço privado.

${ }^{1}$ O Artigo 803 do Código de Processo Penal Francês, introduzido pela Lei de 4 de janeiro de 1993, consagra o princípio de exceção do emprego das algemas, caráter excepcional confirmado pela circular de aplicação da lei de 15 de junho de 2006 (Ministério da Justiça, Circ. Crim - 00 -13/F1, de 4 de dezembro de 2000, em vigor em 1o de janeiro de 2001). 
Sociologias, Porto Alegre, ano 16, no 37, set/dez 2014, p. 306-318

A arma de fogo tem um valor simbólico maior que o seu valor de uso, mas as possibilidades de benefícios simbólicos são, sem embargo, custosas, pois ao se sacar uma arma sempre há exposição de terceiros a um perigo letal. Há uma exposição desnecessária das armas de fogo na maioria dos casos e ações policiais observados, o que confirma a economia da demonstração de poder que se enraíza em uma relação simbólica com o poder estatal, que inclui o poder de matar ou de permitir a vida (p. 74-77).

Tem-se o corpo como que totalmente assimilado a uma máquina a que se pretende provar as engrenagens e calcular a resistência. Através das práticas sobre os corpos, os policiais fazem com que os marginais tenham sua posição e a posição que eles ocupam na sociedade. A anomia convida à degradação. A degradação social se mistura à degradação física e à degradação judicial (p. 104).

Na segunda parte da obra, denominada A prova dos fatos, Jobard apresenta os fatos policiais e os fatos jornalísticos como faces do mesmo problema que se elevaram ao valor de testemunhos de convenções narrativas estabelecidas em um ambiente particular; testemunhos originais submetidos ao fato de não poder discernir entre o verdadeiro e o imaginário, e isso pelas condições de sua vida social e de sua vida moral. A partir desse ponto, o autor apresenta as estatísticas policiais francesas que se referem às ocorrências com uso de armas de fogo por parte dos policiais e por parte das pessoas abordadas, sendo tais informações marcadas pela dispersão, o que dificulta um aprofundamento na temática. Em seguida, ele apresenta as estatísticas das violências policiais sem o uso de armas de fogo, com destaque ao número de arquivamentos das denúncias contra os policiais, cerca de 4/5 (quatro quintos). Para compreensão da face jornalística da questão, Jobard trabalhou sobre as publicações da imprensa nacional francesa no período entre dezembro de 1986 e novembro de 2001.Os fatos policiais se apresentam para a imprensa sob uma forma não singularizada, que pela 
definição não permite a coleta precisa dos fatos. Há uma concentração da imprensa francesa sobre os fatos que se passam em Paris, com foco nos acontecimentos mais espetaculares (como mortes violentas), flutuação conjuntural da atenção midiática (como o retorno de Charles Pasqua ao Ministério do Interior no ano de 1993), concentração pontual sobre tal situação local ou sobre tal comissariado (a morte do jovem Makomé M'Bowolé, em abril de 1993), dependência das redes locais dos correspondentes da Agência Francesa de Notícias (AFP), forte institucionalização das relações entre os jornalistas especializados e os policiais, etc.

Para Jobard, os acontecimentos analisados têm em comum o fato de mostrarem que casos de violência policial portam um cálculo por parte dos policiais agressores com o fim de evitar testemunhos e tornar a violência menos visível. Nada sustenta a afirmação de existência de uma antecipação calculada, mas os casos estudados, além de violentos, foram visíveis; no entanto, as ações que informaram à imprensa foram raramente consideradas, ao ponto de não deixar rastros aparentes.

Os relatos de quem saiu da prisão foram submetidos por Jobard a um duplo teste de validez externa, com base nas estatísticas disciplinares da polícia, que constituem as operações de agregação, e as notícias policiais divulgadas na imprensa, que fazem parte das operações de singularização (p. 144). O autor encontrou uma sobreposição nos modos de acreditar da imprensa e da justiça, o que nos obriga a colocar à prova os fatos através das instâncias que se encarregam de lhes dar publicidade. Resta a indagação, não só no que se vê entre a testemunha e o depositário do testemunho, mas também no que, do lado da polícia, a justiça ou a imprensa, influi na vontade da mesma em testemunhar ou de tomar conhecimento do testemunho. As propriedades sociais das vítimas dos fatos de violência policial publicados pela imprensa acumulam características similares de isolamento 
com relação ao exterior, baixos recursos sociais e forte proximidade com os policiais, o que fragiliza a credibilidade social de seus testemunhos.

Em seguida, Jobard continua o seu trabalho analisando os fatos de violência policial que foram convertidos em casos judiciais, tomando como base o período entre os anos de 1982 a 1987. Descobre que a polícia dispõe de um meio quase invencível de desacreditar as acusações contra seus agentes. As testemunhas das violências policiais estão sob a tutela do adágio 'testusunus, testisnullum', ou seja, a vítima se transforma na única testemunha do fato que alega e sua pretensão de admissibilidade de acusação é aniquilada, salvo, por exemplo, que logre dar materialidade e visibilidade ao vínculo entre os fatos alegados e as ações policiais que os causaram. Isso demanda uma mobilização de provas materiais e/ou testemunhais. As testemunhas devem ter boa moral, mas a biografia das mesmas e da vítima não está dada, ela é elaborada no transcurso da ação de justificação.

A trama de silêncio se fecha sem cerimônia sobre as violências policiais, selada nas dobras e vincos das mostras probatórias. A violência ilegítima pode se refugiar detrás de uma causa de ultraje, de rebelião ou de violência contra os agentes policiais. Há uma presunção de legitimidade acordada entre os policiais e os modos como a justiça examina as denúncias apresentadas, deduzindo-se que a única garantia de ver estabelecido o alegado é a qualidade de homem sem qualidades penais, comprovando aquilo que Jobard denominou de pureza penal. A violência policial como fato deve sua identificação a suas condições providenciais de ocorrências (flagrante constado por terceiros "puros", pistas deixadas por indícios irrefutáveis) e à irrefutável pureza moral (ao invés de social e penal) da vítima. É essa dupla condição de estabelecimento do fato, jamais estabilizada, que precisamente exclui da identificação da violência policial aqueles que sabemos serem suas vítimas mais prováveis, como os egressos da prisão (p. 149-180). 
Dar força à lei é a terceira parte da obra resenhada, onde Jobard prefere escutar o silêncio, compreender tudo o que se trama em torno dos fatos que nunca puderam ser escutados, delineando os espaços de probabilidade dessas violências, o espaço onde a violência policial tem todas as possibilidades de se produzir e onde pode ser silenciada. Como condição de ocorrência dessa violência, o autor destaca: 1) a anomia das pessoas com maior probabilidade de serem vítimas de violência policial é o fermento de seu fracasso social e penal; 2) os territórios onde se mantém uma conversa singular com a polícia são aqueles sobre os quais os mediadores de opinião pública não se aventuram; e 3) o rendimento da polícia judiciária é, também, pressuposto, pois marca o fim do êxito da repressão do crime e das desordens das quais participa a justiça (p. 183-184).

A passagem ao ato de violência policial é, doravante, vista em suas condições sociais (o mundo no qual se envolve) e jurídicas (os textos que disciplinam a intervenção policial). Existem dois motivos que podem pôr em marcha a ação policial. Caso aconteça uma infração penal, a polícia intervém e abre-se uma investigação, seja por flagrante delito ou por uma prisão em cumprimento de mandado judicial para constatar as infrações, reunir provas e buscar autores. Se não aconteceu nenhuma infração penal, a polícia também pode intervir sobre a base de suspeita para efetuar um controle preventivo que permita acabar com o perigo iminente ou, caso necessário, para impedir o cometimento de uma infração.

Os relatos de quem passou pela prisão demonstram que os controles e verificação de identidade estabelecem um jogo de espelhos entre a habilitação jurídica (os indícios que permitem o controle) e os mecanismos comportamentais (os alarmes que solicitam controle). O temor de ser controlado provoca uma modificação de atitude, e esta modificação justifica o controle de identidade; soma-se a esse comportamento o fator territorial que, dependendo de sua representação de periculosidade, 
legitima o controle de identidade por se converter em zona notadamente perigosa. Para atuar, a polícia consolida a arena policial,onde o emprego de força é um instrumento privilegiado de intervenção. Há uma interpretação das leis pela polícia, de modo que esta possa se cercar nas ações e confundir os malfeitores. Ocorre, então, o processo sociológico de etiquetamento,no qual a equação estar em alguma parte e ser alguém está inserida na lei, submetendo-se a liberdade de ir e vir a uma exigência prévia de aparência normal (p. 185-188).

Anota Jobard uma crescente codificação do controle e do formalismo dos procedimentos policiais. No entanto, a multiplicação de regras tem um custo de uso que se mostra perfeitamente desmedido com relação às limitações pragmáticas que pesam sobre os atores. Enquanto o trabalho policial consiste no estabelecimento de certo número de operações simples em um tempo limitado (verificar a identidade), o tempo necessário para a aprendizagem e a utilização dessas regras se convertem em obstáculos para a realização da missão policial prevista. Os magistrados, responsáveis pelo julgamento dos atos levados ao seu conhecimento, substituem seu dever de controle por uma confiança quase absoluta nos procedimentos formais estabelecidos pelos policiais. Essa operação de ordenamento simbólico da prática policial reforça a solidez da arena policial. A população, objeto potencial da força policial, está marcada por recursos sociais (homens jovens desempregados), situacionais (no espaço público) e penais (objetos de atenção da polícia) recorrentes.

Essas arenas de jogo tenso, submetidas ao risco permanente de uma subida ao extremo, não foram construídas por um corpo policial que prefere o poder ou a repressão. Ao contrário, os dados demonstram a estabilização e a consolidação das trajetórias históricas distintas, pois se alimentam reciprocamente. Por um lado, a cristalização da violência física como modo de gestão da vida em sociedade, cada vez mais difícil e 
contraditória, imposta aos jovens dos bairros pobres das grandes cidades. Por outro, políticas públicas que se limitam ou à contenção da violência através da ocupação provisória dos jovens (políticas que sempre tropeçam no fato de seus destinatários não terem relação duradoura no mercado de trabalho, mesmo quando migrantes), ou à submissão desse público aos serviços repressivos (polícia e justiça) como oferenda estatal dirigida a esses jovens (p. 205).

Duas gramáticas se enfrentam. De um lado, a gramática das relações interpessoais, baseada nas lógicas da anomia, do território e do rendimento, onde a violência é um meio recorrente de intercâmbio. Do outro, a gramática das disposições jurídicas, que tentam conhecer nas prescrições alguns dos princípios fundamentais do direito, como o respeito à dignidade humana. As disposições sobre os controles de identidade, sobre a investigação da polícia e o flagrante delito ou a detenção provisória mostram que, na maioria das vezes, a confrontação das gramáticas resulta na dissolução do direito nas práticas existentes, mediante a absorção de uma gramática pela outra. Ou seja, a prática ignora o direito, demasiadamente complicado e formalizado, danoso às rotinas policiais estabelecidas. Há um acoplamento entre todo o espaço limitado de relações interpessoais e o direito (p. 206-235).

Na conclusão, o autor retoma a narrativa de intenção de seu projeto, que foi investigar o monopólio da violência física legítima com foco nas manifestações do uso da força pela polícia francesa, sobretudo as consideradas ilegalismos, cuja economia de meios das formas de emprego converge a uma estratégia de controle dos corpos, que respondem aos imperativos determinados pelo direito, superando-os. As violências policiais estão em um espaço estranho, colocando em cena uma dominação do corpo do indivíduo em relações que são consolidadas mediante um conjunto de disposições e mecanismos objetivos. Jobard questiona se o 
monopólio da violência física legítima ocupa lugar central na teoria sociológica do Estado e qual o papel e o lugar das violências excepcionais. Afirma que, para entender o uso da força por parte da polícia, é necessária uma análise localizada, na qual a reconstrução empírica do espaço das violências policiais permita ver claramente que, em matéria de ordem pública, existe um espaço excepcional de autoridade concedida à polícia, onde a norma rotineira e a decisão excepcional são distintas e a norma jurídica e a violência física se reconciliam, tornando uno norma e fato.

Leitura essencial para quem estuda o Estado, a violência (legítima e ilegítima) e a polícia, sua contribuição é de grande valia para a Sociologia da Polícia. Pelo trabalho que tem realizado, podemos afirmar que Fabien Jobard é um dos grandes expoentes na nova geração das ciências sociais na França.

Edson Benedito Rondon Filho. Doutor em Sociologia pela Universidade Federal do Rio Grande do Sul, na linha de Violência, Criminalização, Cidadania e Direito, com estágio doutoral (sanduíche) junto ao Centre de Recherche Sociologique sur le Droit e les Institutions Pénales (CESDIP) / França. Mestre em Educação pela Universidade Federal de Mato Grosso. Especialista em Inteligência de Segurança Pública pela FAECC - UFMT. Especialista em Gestão de Segurança Pública pela FAECC- UFMT. Docente convidado da Pós-graduação em Direitos Humanos aplicados à Segurança Pública da Universidade Federal de Mato Grosso. Docente de Criminologia do curso de Direito da Faculdade Católica Rainha da Paz (FCARP). $\checkmark$ edsonrondon@hotmail.com

Recebido em: 05/08/2013

Aceite final: 10/11/2013 